\title{
Herbicide Tolerant Food Legume Crops: Possibilities and Prospects
}

\author{
N.P. Singh ${ }^{1}$ and Indu Singh Yadav ${ }^{1,2}$ \\ ${ }^{1}$ Indian Institute of Pulses Research, Kanpur \\ ${ }^{2}$ National Research Centre on Plant Biotechnology, New Delhi, \\ India
}

\section{Introduction}

Weeds are one of the major problems in agriculture. Weeds compete with other crops for water and nutrients and, as a result, decrease yields and productivity. Without weed control it is extremely difficult to harvest crops. The advent of mechanization replaced much of the hand labour in the developed world as well as the developing parts of the third world. Mechanical weed control is fraught with high-energy costs, facilitates soil erosion and compaction and has been mostly replaced by chemical weed control using herbicides (Gressel J, 2000). As countries industrialize and develop economically, cheap farm labour becomes unavailable, thus increasing the necessity for cost-effective chemical weed control. In India, weeds cause the highest loss (33\%) followed by pathogens (26\%), insects $(20 \%)$, storage pests $(7 \%)$, rodents $(6 \%)$ and others $(8 \%)$. It has been estimated that the potential losses due to weeds in different field crops would be around 180 million tonnes, valued at Rs. 105,0000 millions annually (Anonymous, 2008). Globally, herbicide constitutes 50 percent of the total pesticides sale and in some countries like USA, Germany and Australia; the figure is as high as 60-70 percent. In India, however, the position is different as herbicides form a meager 15 percent of the total pesticide consumption. But still, the consumption has increased rapidly from 4100 metric tons (MT) in 1988-89 to 13,764 MT in 2004 and it is likely to further increase in future (Varshney and Mishra, 2008). Given the harmful economic implications of poor weed management, it is hardly surprising that herbicide production is a main driver of the agrochemical industry. Too often there is no selective chemical that can control a particular weed in a particular crop, as most selectivity between crop and weed are due to catabolic degradation of the herbicide by the crop. Therefore, closely related weeds are to be expected to have similar catabolic pathways as the crop and thus escape the chemical effect. This is one major reason that genetically modified herbicide-resistant crops (GM-HRC) have become so useful, and that biotechnology has been utilized to produce such crops as well as to find new herbicide targets. Selectivity can be enhanced by inserting exogenous resistance genes into the crops or by selecting natural mutations. However, one major concern about transgenic herbicide resistant crops (HRCs) is that the transgene could genetically introgress into related weeds, and make them resistant and therefore, their careful management comes into account. 


\section{Chemical weed control}

The controlling of weeds in the growing crops with weedicides increases their yields and ensures the efficient use of irrigation, fertilizers and plant-protection measures, such as the spraying of insecticides and fungicides. The removal of weeds from the growing crops facilitates easy harvesting and gives a high-quality produce without admixture with weed seeds. Chemical weed control can be adopted quite in time and in situations and under conditions, which make manual or mechanical weeding difficult. A great advantage of this method lies in killing weeds in the crop row or in the immediate vicinity of crop plants. The chemical method is easier, less time-consuming and less costly than weeding by hired laborers. However, there are several disadvantages like environment pollution, human and animal health issues related to its use.

\section{Biological weed control}

Biological weed control is the action of parasites, predators, or pathogens to maintain another organism's population at a lower average density than would occur in their absence. Biological control is usually thought of as intentional introduction of parasites, predators, or pathogens to achieve control, but it is also a natural phenomenon. Biological control will never be the solution to every weed problem. It is employed as one weed management practice among many. Using tools of biotechnology, it is possible to engineer a more potent parasite, predator or mutant which can be deployed to weed control. The biological weed control can be permanent weed management because once an organism is released, it may be self-perpetuating and control will continue without further human intervention. Besides, there are no chemical environmental residues from biological control other than the organism. Bio control may be the best option for management of invasive species. In ideal cases, initial costs are nonrecurring and usually, once the organism is established, no further inputs are needed. There are some situations where biological control is not appropriate. If a plant is a weed in one place and valued in another place, in the same general geographic region, biological control is inappropriate. Spread of a biological control organism, once introduced, cannot be controlled. Biological control is inherently slow, and results are not guaranteed. Some species are geographically local, minor weeds, and development of a biological control for them would be very expensive and not financially wise because of the small-infested area. Release of a biological control organism can induce competitive suppression or extinction of native biological control organisms and other desirable organisms. Biocontrol, particularly in disturbed cropping situations, will not control as many different weeds as other techniques. It won't eradicate weed problems, but most other techniques won't either.

\section{Biochemistry and molecular biology of weed control}

The need for developing cost effective chemical weed control systems has led to a vast industrial investment to find and develop selective herbicides and later GM-HRC. Virtually all herbicides marketed are the result of random screening of chemicals. Once success is obtained, further syntheses around the identified chemical are used to find compounds with greater activity and then selectivity. After such compounds have been 
found and marketed, they become research tools of the physiologists and biochemists, first to find a site of action and then as 'anti-metabolites' to further understand and modulate metabolic pathways. Thus the advent of 2,4-D assisted in understanding auxin action, atrazine and diuron (DCMU) in understanding photosystem II, paraquat for photosystem I, dinitroanilines in tubulin to microtubule assembly, dichlobenil for cellulose biosynthesis, etc. Herbicides are the anti-metabolites of choice in dealing with key enzymes such as glutamine synthase [glufosinate (phosphinothricin)], acetolactate synthase (ALS) (many herbicides), acetyl-CoA carboxylase (ACCase) (many herbicides), dihydropteroate synthase (asulam), enolpyruvate-shikimate phosphate synthase (EPSP) (glyphosate) and phytoene desaturase (many herbicides). The genes for most of these enzymes have been isolated and used in transgenic programs. Such research transcended plant biochemistry and agriculture. For example, it was discovered through comparative genomics that plant and trypanosome $\beta$-tubulins were similar to each other and different from mammalian $\beta$-tubulin. The dinitro-aniline herbicides then proved to be excellent trypanocides (Chan et al., 1993; Bell, 1998). The repetitive (mis) use of single herbicides in monoculture over many years predictably leads to the evolution of herbicide-resistant weeds (Gressel \& Segel, 1978). The advent of triazine resistance was crucial to the understanding of the role of the $p s b \mathrm{~A}$ gene product in the photosystem II binding site, leading to innumerable studies of photosynthesis, biophysics and biochemistry correlated with molecular structure of the gene product. The mutant and natural $p s b$ A gene products were crystallized and analyzed, leading to new insights into 'drug' (ligand) binding and design (Michel \& Deisenhofer, 1988; Deisenhofer \& Michel, 1989). Information from herbicide resistance provided the theoretical underpinning for designing transient drought resistant plants. Harvey and Harper (1982) first promoted the idea that paraquat resistance can be similar to oxidative stress tolerance. This was later extrapolated to being similar to transient drought tolerance (Malan et al., 1990). This has allowed developing quick pre-tests with paraquat to ascertain the level of transient drought tolerance of transgenic plants bearing genes designed to confer oxidative stress resistance. Genes coding for herbicide resistance developed for agriculture became the selectable markers of choice for generating transgenics, supplanting antibiotic resistance, even when there was no plan for registering the herbicide for use in that crop. The huge corporate investment in HRC and Bacillus thuringiensis (Bt) toxin containing crops due to perceived market size resulted in the gain of much of our knowledge on promoters, organelle-specific and transit peptides, as well as more recently in organelle transformation. This corporate investment in basic plant molecular biology was manifold greater than the public sector effort, and the spill-over was great. It is important to understand that the transgenic research is market driven and the market is for weed control.

\section{Recombinant DNA technology used to achieve herbicide resistance}

The techniques used to achieve herbicide tolerance have been reviewed by Cole (1994). Crops which have been transformed to become herbicide tolerant include are shown in Table 1.

In general, the herbicide tolerance gene is expressed as a determinant which is integrated at a single nuclear locus. Tobacco has often been used as a model crop to study and optimise alien gene performance; this reflects the ease of transformation in this species. 


\begin{tabular}{|l|l|l|l|l|}
\hline Herbicide & Novel gene product & $\begin{array}{l}\text { Gene } \\
\text { Function }\end{array}$ & Gene Source & $\begin{array}{l}\text { Transformed } \\
\text { agricultural } \\
\text { crops }\end{array}$ \\
\hline Sulfonylureas & Acetolactate & mts & Higher plant & $\begin{array}{l}\text { Chicory, cotton, } \\
\text { flax,lettuce, } \\
\text { lucerne, melon, } \\
\text { sugarbeet, } \\
\text { tomato }\end{array}$ \\
\hline Imidazolinones & Acetolactate synthase & mts & Higher plant & Tobacco \\
\hline Glyphosate & $\begin{array}{l}\text { Enolpyruvylshikimic } \\
\text { acid phosphate synthase }\end{array}$ & mts & $\begin{array}{l}\text { Soil and } \\
\text { enteric } \\
\text { bacterium, } \\
\text { higher plant }\end{array}$ & $\begin{array}{l}\text { Rape, soybean, } \\
\text { tomato }\end{array}$ \\
\hline Atrazine & $\begin{array}{l}\text { Glyphosate } \\
\text { oxidoreductase }\end{array}$ & detox & $\begin{array}{l}\text { Soil } \\
\text { bacterium }\end{array}$ & $\begin{array}{l}\text { Maize, rapeseed, } \\
\text { soybean }\end{array}$ \\
\hline Glufosinate & N-acetyl transferase & detox & Bacterium & Coybean \\
\hline Bromoxynil & Nitrilase & detox & $\begin{array}{l}\text { Soil lucerne } \\
\text { bacterium }\end{array}$ & $\begin{array}{l}\text { Cotton, potato, } \\
\text { rape, tomato }\end{array}$ \\
\hline 2,4-D & Mono-oxygenase & detox & $\begin{array}{l}\text { Soil } \\
\text { bacterium }\end{array}$ & Cotton \\
\hline
\end{tabular}

Table 1. Transformation of crop species for herbicide tolerance.

\section{Mechanisms for conferring herbicide tolerance in crops}

Tolerance to herbicides can be achieved by various mechanisms and genes:

a. bar gene

Members of the genus Streptomyces (Actinobacteria: Actinomycetales) produce hundreds of antibiotics, one of which is bialaphos (also known as bilanafos or PTT). Its chemical structure is given below (Fig 1). Bialaphos is an inhibitor of the key enzyme in the nitrogen assimilation pathway, glutamine synthetase (GS). It becomes active after removal of the alanine residues by intracellullar peptidases. The remaining glufosinate compound inhibits GS and as a result leads to accumulation of toxic levels of ammonia in bacteria and plant cells.

\section{Bialaphos}<smiles>CC(NC(=O)C(C)NC(=O)C(N)CCP(C)(=O)O)C(=O)O</smiles>

\section{phosphinothricin-alanyl-alanine}

Fig. 1. Structure of bialapos. 
Some microorganisms can detoxify glufosinate by producing an enzyme that causes acetylation of the amino group. The gene encoding the acetylating enzyme has been isolated from Streptomyces hygroscopicus (Thompson et al., 1987) and from S. viridochromogenes (Wohlleben et al., 1988). It has been referred to as bar (for bialaphos resistance) and PAT gene, respectively. The bar gene encodes a phosphinothricin acetyl transferase (PAT). In the few countries commercial transgenic crops such sugar beet, canola, soybean, rice and maize carrying the bar gene has already been released and cultivated commercially.

b. Detoxifying enzyme coding gene

Continuous search for new herbicides that are highly effective and safe for animals and the environment is the need of the hour. A new class of herbicides that fulfils these needs acts by inhibiting specific amino acid biosynthesis pathways in plants (La Rossa 1984). However, most of these herbicides do not distinguish between weeds and crops. Modifying plants to become resistant to such broad-spectrum herbicides would allow their selective use for crop protection. As a consequence, a major effort has been devoted in several laboratories to engineer herbicide-resistant plants. Two approaches have been followed. In the first, a mutant form of the target enzyme is produced which is still active but less sensitive to the herbicide. In this way, mutant plants producing an altered form of the enzyme acetolactate synthase have been selected which are resistant to the sulfonylurea and imidazolinone herbicides (Shaner and Anderson, 1985). In another example, a mutant form of the bacterial aro A gene was expressed in tobacco and conferred tolerance to the herbicide glyphosate (Comai et al., 1985). The second approach involves overproduction of the target enzyme. It has been demonstrated that overexpression of the plant enzyme 5-enol-pyruvylshikimate- 3 phosphate synthase conferred glyphosate tolerance in transgenic petunia plants (Shah et al., 1986).

Glyphosate was released by Monsanto Chemical Co. in 1971. Its discovery and release were as revolutionary in weed science as the discovery of 2,4-D. The structure of the amino acid glycine is underlined in following Figure.2 Glyphosate, the Nphosphonomethyl derivative of glycine, is a nonselective, foliar herbicide with limited to no soil activity because of rapid and nearly complete adsorption. It controls perennial grasses and has an advantage over paraquat, because glyphosate translocates. It is the only available herbicide that inhibits EPSP synthase. The enzyme is common in the synthetic pathways leading to the aromatic amino acids phenylalanine, tyrosine, and tryptophan. These amino acids are essential in plants as precursors for cell wall formation, defense against pathogens and insects, and production of hormones (Duke, 1990). The enzyme is not found in animals. Low application volume is more effective than high volume, and small plants are more readily controlled than large ones. In contrast, paraquat, a photosynthetic inhibitor, acts quickly (one or two days) on most plants. Glyphosate activity usually cannot be detected as quickly and may take several days to appear after application. One glyphosate formulation is also used as an aquatic herbicide. Transgenic crops resistant to glyphosate have been developed and marketed. Resistant species include Palmer amaranth, common ragweed, hairy fleabane, goosegrass, Italian ryegrass, rigid ryegrass, and buckhorn plantain. Resistance has been found in Australia, Chile, South Africa, Spain, and in 15 US states. 


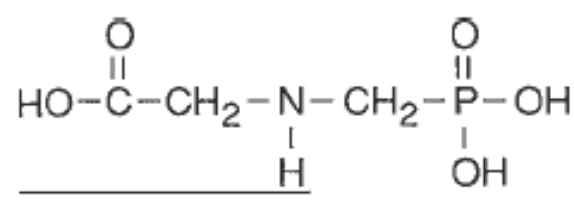

Fig. 2. Structure of glyphosate with glycine underlined.

\section{Glutamine synthase}

Glutamine synthetase (GS) is essential for assimilation of organic nitrogen as ammonia (Duke, 1990). Glufosinate (phosphinothricin) is the only available herbicide that inhibits GS. It is available in the United States for complete weed control in non crop areas and as a directed spray in field- and container-grown nursery stock. It is rapidly degraded in soil with a half-life of seven days. Even though it is not adsorbed tightly, it does not leach because it is degraded quickly. Glufosinate is nearly nonselective. It has been made selective in corn because a gene coding for phosphinothricin acetyl transferase activity was isolated from the soil bacteria, Streptomyces hygroscopicus, and cloned into corn. The acetyl transferase enzyme converts glufosinate to its nonphytotoxic acetylated metabolite, enabling crops to achieve resistance by rapidly metabolizing glufosinate.

\section{Uses of molecular data in weed control}

Not all applications of molecular biology are commercial. There is a necessity to taxonomically classify weeds, as there are differences in selective control among related weeds, as epitomized with weeds of the genus Amaranthus (Mayo et al., 1995). Indeed, the classical taxonomy is so complicated that it was found using molecular techniques that many accessions of wild species in the collections were mis-classified (Martin et al., 1997). Molecular taxonomy has been of great assistance and has often provided the decisive data in many cases on whether two similar Amaranthus species were actually one, or were separate, or were hybrids, depriving classical taxonomists of their endless battles. Knowing relatedness will be required for assessing the risks of crop gene introgression into weeds, and has been used to trace whether a biotype evolved resistance by introgression, vs. by its own internal mutation (Wetzel et al., 1999b). This is very important to know, as the wild species do not introgress freely with cultivated species and the feral form does exist (Morishima, 1984; Ling-Hwa \& Morishina, 1997; Mariam et al., 1996; Majumder et al., 1997; Cohen et al., 1999). Most of the present uses of molecular biology are to find new herbicide targets and to generate HRC.

\section{Herbicide tolerance}

After using an herbicide continuously to control a weed over time, it may no longer be effective in controlling that weed. In other words, the weed species becomes resistant to the herbicide and is no longer controlled by it. However, the entire population of the weed species may not necessarily behave in the same manner; some members of the same species may still be controlled by the herbicide. There are two basic processes by which herbicide 
tolerance develops. Most of the time, it develops as a result of selection pressure. In this case, a very small fraction of the population of a particular weed species may possess a slightly different genetic makeup from the rest of the population -- referred to as a biotype -that makes it tolerate herbicide " $X$ " the first time it is used. Another process by which resistance develops is through mutations. In this case, one or more members of a weed species undergo a change in genetic makeup due to frequent exposure to the herbicide. The modifications usually occur at the site where the herbicide binds at the target site in order for it to be effective.

The mode of action is the mechanism by which a given herbicide travels to a target site within a plant where it exerts activity by inhibiting a growth process vital to the plant. Certain families of herbicides may inhibit the process of photosynthesis. Others may inhibit the synthesis of chlorophyll or amino acids vital to plant's growth, still other groups may cause leaks to plant cells resulting in plant kill. If a weed species develops resistance to two or more herbicides belonging to the same family, the phenomenon is called Cross Resistance. If it develops resistance to two or more herbicides belonging to different families, it is called Multiple Resistance.

There are three physiological mechanisms for natural or induced tolerance or resistance to an herbicide:

1. Reduced sensitivity at a molecular site of action,

2. Increased metabolic degradation, and

3. Avoidance of uptake or sequestration (hiding) after uptake (Duke et al., 1991).

Each of these has potential use in development of resistance in crops. Most of those modified to be resistant to glyphosate and glufosinate are commercially available and grown. Roundup Ready TM soybeans, corn, cotton, and canola have achieved commercial success in the United States and Canada. Other glyphosate-resistant crops are being developed by Monsanto.

The primary cause of herbicide resistance is selection pressure or repeated use of the same herbicide or other herbicides with the same mode of action. Therefore, the most effective step is to use all possible methods of weed control rather than depending upon a single tactic. This helps to avoid the use of the same or similar herbicide repeatedly. An Integrated Pest Management (IPM) method that encompasses cultural, mechanical, chemical, and biological control methods, rotating with different families of herbicides, tank-mixing herbicides having different modes of action, and occasionally using a non selective herbicide to control all weeds are practical methods to reduce resistance buildup. Resistance is real and widely present, but it can be managed. It is well understood that it results from repeated use of the same herbicide or herbicides with the same mode of action in fields. It is not created by the herbicides; it is selected for. The plants that are susceptible are killed. The resistant population survives and comes to dominate. It is a process of evolution by chemical selection. The time for development of resistance has proven to be short. Several species have evolved cross-resistance to more than one herbicide. Since 1982 the number of resistant weeds has more than tripled, and the land area involved has increased 10 times. Multiple resistances have been observed and occur when resistance to several herbicides results from two or more distinct resistance mechanisms occurring in the same species. In general, but not always, there are enough alternative herbicides and other control measures 
(e.g., rotation, tillage) to manage resistant weeds effectively. Resistance to some of these herbicides has developed in as little as three years. It is equally incorrect to assume that the phenomenon of resistance is the death knell for herbicides. Resistant weeds are not super weeds and are often less fit ecologically than their susceptible relatives. It is important to recognize that resistance is possible and to determine the reasons for it. Management of herbicide resistance will require reducing reliance on herbicides as the primary tool for weed management and developing integrated weed management systems that require the substitution of human intellect and skill for chemical technology (Shaner, 1995).

Most Important herbicide resistant crops are given bellow:

$\begin{array}{ll}\text { 1. } & \text { Rigid grass } \\ \text { 2. } & \text { Wild oat } \\ \text { 3. } & \text { Redroot Pigweed } \\ \text { 4. } & \text { Common Lambsquarters } \\ \text { 5. } & \text { Green Foxtail } \\ \text { 6. } & \text { Bamyardgrass } \\ \text { 7. } & \text { Goosegrass } \\ \text { 8. } & \text { Kochia } \\ \text { 9. } & \text { Horseweed } \\ \text { 10. } & \text { Smooth Pigweed }\end{array}$

\section{Herbicide resistance GM crops}

Genetically modified crops are the most rapidly adopted technology in agricultural history due to the social and economic benefits these crops may offer. Crops that are genetically altered to be tolerant to herbicide, followed by crops resistant to insects, were the first agricultural biotechnology inventions successfully commercially exploited worldwide. Until the emergence of genetically modified crops, selective herbicides (herbicides that only kill a specific weed) were the answer. The development of selective herbicides is not an easy task and for this reason only a few common weed species could be targeted. Given that each weed requires a different herbicide, herbicide application was frequent, in large volumes and very costly. The advent of herbicide resistant crops caused a major shake-up in the agro-chemical industry. Demand for selective herbicides fell significantly. In certain countries, for the crops that have herbicide resistance, are widely planted and otherwise non-selective (broad spectrum) herbicides are primarily used for weed management. Provided that the field crops are genetically modified to carry gene(s) for herbicide resistance, these broad-spectrum herbicides will not harm the crop. Broad-spectrum herbicides, such as glufosinate and glyphosate, are comparably biodegradable, display low levels of toxicity, and to date, weeds have shown minimal resistance to repeated applications. Resistance to these broad-spectrum herbicides depends upon the genes that have been inserted into the crop plant.

\section{Global scenario}

The global area planted with transgenic crops is increasing continuously and according to the recent data available (2010); the total global area of transgenic crops is 148 million hectares, a more than 48 fold increase from 1996. More than eight and a half million farmers 
in 28 odd countries have grown transgenic crops. The majority of the growth occurred in the United States (63\%), Argentina (20.5\%), Canada (6.5\%) and Brazil (4.4\%). Almost one third $(30 \%)$ of the global acreage was grown in developing countries. Total area under transgenic crops in India is around 9.4 million hectare. In 2003, herbicide resistant crops made up $73 \%$ of the total genetically modified (GM) crop-growing area, while insect resistant crops constituted 18\%. GM crops containing genes for both herbicide resistance and insect resistance comprised $99 \%$ of the total GM crop growing area. It is expected that the overall global area of transgenic crops and the number of countries growing transgenic crops will increase in near future. Currently, the agricultural GM market is dominated by a single company, Monsanto. Monsanto produces approximately $90 \%$ of genetically engineered crops worldwide. This most likely reflects the ownership by Monsanto of patents on the bar gene which confers herbicide resistance as well as patent ownership of various $B t$ toxin genes for insect resistance. Another four companies, Syngenta, Bayer Crop Science, Dow and DuPont produce the remaining 10\% of transgenic crops. All major herbicide companies have research programs to incorporate herbicide tolerance through genetic engineering in crops. Success has been achieved with several herbicides. The work has focused on major crops: corn, soybean, wheat, rice, cotton, and tobacco. The technology for agricultural crops was introduced as early as the mid-1980s.

\section{Metabolically resistant genetically modified - herbicide resistant crops (GM-HRC)}

Many crops bearing transgenes coding for highly specific enzymes that metabolically catabolize herbicides have been generated (Cole \& Rodgers, 2000). These include for example, bromoxynil resistance crops bearing a nitrilase (Freyssinet et al., 1996), glufosinateresistant crops bearing an acetyl-transferase (Vasil, 1996), 2, 4-D resisting crops bearing a highly specific soluble cytochrome P-450 monooxygenase (Streber \& Willmitzer, 1989), phenmidipham resisting crops bearing a bacterial gene and dalapon resisting crops bearing a dehalogenase (Buchanon-Wallaston et al., 1992). Of these, only the bromoxynil- and glufosinate resistant crops have reached commercialization. All the herbicide tolerant genes used commercially are of bacterial/ actinomycete origin, despite the fact that plants contain genes for herbicide resistance, which is the basis for most natural metabolic selectivity used for 50 years, yet plant genes conferring metabolic resistance have not been used commercially as yet. There are recent reports using non-prokaryotic genes to confer resistance, but none are yet commercialized, and whether they confer sufficient resistance is not clear. The examples include a rabbit esterase gene conferred resistance to thiazopyr via degradation (Feng et al., 1998), the expression of plant and animal P450 transgenes conferred phenyl urea resistance (Inui et al., 1999; Siminsky et al., 1999). Transgenes encoding maize glutathione transferases increased the level of herbicide resistance (Jepson et al., 1997). The crops generated with metabolic resistance seem to be problem-free, with little metabolic load conferred by generating the small amount of enzyme needed. The toxicology is simplified because the transgene product typically initiates a cascade of events whereby the herbicide eventually disappears. There has been an assumption that one cannot use catabolic enzymes to confer resistance to fast acting herbicides. However, inhibitors of protoporphyrinogen IX oxidase (protox), which actually cause the accumulation of the photodynamically- toxic product induce photodynamic death of plants within $4-6 \mathrm{~h}$ in bright sunlight. Beans are immune to some members of this group, e.g. acifluorfen, because 
they possess a specific homoglutathione transferase and contain enough homoglutathione to stoichiometrically degrade these herbicides before they can damage the crop (Skipsey et al., 1997). Similarly, strains of Conyza bonariensis contain a complex of enzymes capable of detoxifying the reactive oxygen species generated by the photosystem I blocker paraquat, and keeping the plants alive until the paraquat is dissipated (Ye et al., 2000; Ye \& Gressel, 2000). As almost all herbicides are either degraded in the soil or in some plant species, one should be able to find more genes for catabolic resistance to those herbicides and then be able to rapidly generate herbicide-resistant crops with metabolic resistance than with target site resistance.

\section{The success of genetically modified herbicide resistant crops (GM-HRC)}

Millions of hectares are being planted with GM-HRC, with insect resistance in second place, with both traits often 'stacked' in the same seeds to enhance their value. The real values of GM-HRC come from instances where there really are no viable weed control methods (e.g. due to evolved herbicide resistances in weeds), and the impact that such GM-HRC could lead to a more sustainable world food production. The easiest way to obtain selectivity among closely related species is to engineer resistance to a general herbicide into the crop. For example, it has already been shown that rice (Oryza sativa) is easily controlled by glufosinate. The transgenic rice (Sankula et al., 1997a, b) bearing the bar gene confers resistance to this herbicide (Oard et al., 1996). The immediate answer to multiple resistance problems in weeds of wheat in major growing areas is to engineer resistances to inexpensive herbicides (Gressel, 1988). Neither the chemical nor the biotechnological industries have shown particular interest in generating GM-HRC in wheat, rice, millets, pulses or oilseed crops. As too little profit is perceived to come from wheat, rice or other seed or even from generic herbicides, it may be necessary to have wheat, rice, millets and pulses engineered by the public sector. Glufosinate resistance has been engineered into wheat, more as a marker gene than for agronomic utility (Weeks et al., 1993). GM-HR wheat, rice and food legume crops may be an answer to the major problems of these crops. Inserting a gene into wheat or rice conferring resistance to a broad spectrum herbicide can control weeds that evolved resistance in wheat and even closely-related grasses, including red, weedy, and other wild rices (Gressel, 1999a, b, c). The transgenes will allow problems of resistance that have evolved to be overcome especially, the problems of cross-resistances (where one evolutionary step confers resistance to a variety of chemicals) and multiple resistances (where a sequence of evolutionary steps with different selectors, confers resistance to a variety of chemicals). The use of non-plant transgenes may also allow farmers to overcome the natural resistances in weeds closely related to the crop. The problems of interclass crossresistances and multiple resistances in wheat have necessitated considering the generation of GM-HR oilseed rape, especially in Australia (Gressel, 1999b). Oilseed rape has become an excellent rotational crop alternating with wheat in many places where wheat is grown. There are many agronomic advantages to rotating a dicot with a monocot, especially vis a vis weeds. It should be far easier to eliminate grass weeds in oilseed rape than in wheat, as there are more selective graminicides available for use in dicot crops. There are far too few concrete molecular and biochemical data published about the properties of these crops and thus there are problems in evaluating their properties to allow suggestions for improvements. Thus, some of what will be said below should be considered as speculative. Two types of gene have been used to generate herbicide-resistant crops: (1) where the gene 
product detoxifies the herbicide; (2) where the herbicide target has been modified such that it no longer binds the herbicide. One could envisage other types such as exclusionary mechanisms, sequestration, etc., but they have yet to be found and thus not utilized. The resulting GM-HRC with each type of resistance is rather different.

\section{Herbicide tolerant food legume crops}

The food legumes like chickpea, pigeonpea, fieldpea, lentils, urdbean and mungbean are very important for food and nutritional security of poor people in India. These crops suffer to a great extent $(33 \%)$ due to infestation by weeds. At present no post emergence selective weedicide is available which can be effective to control weeds as these crops are highly sensitive to application of herbicides. Hence, mechanical or manual weeding is considered to be only management options for weed control. In general, food legumes are highly sensitive to available post emergence weedicides. It is, therefore, required to develop resistance/ tolerance in these crops against post emergence weedicides. Development of GM-HRC can be one of the potential options. However, in mid eighty when priorities in area of plant biotechnology were decided in country for developing GM crops, herbicide tolerant was kept out of priority because very cheap agricultural labour were available for these operations in the country. However, with increasing industrialization there is acute shortage of farm labours in the country. Therefore, the need of GM-HRC is realized these days. In view of this, genetic transformation has been successfully attempted in chickpea, pigeonpea and fieldpea with bar gene (used as selectable marker) and stable transformants have been recovered which show considerable degree of resistance to phosphinothricin (Singh et al., 2009). In azuki bean, genetic transformation was done by introducing binary plasmid (pZHBG) comprising the bar gene coding the enzyme, phosphinothricin acetyltransferase which directly inactivates the herbicides phosphinothricin and confers resistance to the commercial herbicides, bialaphos (Confaloneirri et al., 2000). In Cowpea, stable gene transformation was obtained by using particle gun method by Ikea et al., 2003. However, the level of expression of introduced genes in cowpea cells is very low and this accounted for the high mortality rate of progenies under Basta spray. Transgenic plants of the model legume Lotus japonicus were regenerated by hypocotyl transformation using a bar gene as a selectable marker (Lohar et al., 2001). The production of PPT herbicide-resistant L. japonicus plants has shown significant commercial applications in crop production. Brar et al., 1994 developed transgenic plants of peanut of cultivars Florunner and Florigiant, two of the most widely cultivated peanut cultivars in the USA, using the ACCELL ${ }^{\circledR}$ gene delivery method. Gus and bar genes exhibited predictable segregation ratios in the $R_{1}$ and $R_{2}$ generations and were genetically linked. Integration of the bar gene conferred resistance to BASTATM, a wide-spectrum herbicide, applied at 500 ppm of active ingredient. This work has paved the way to develop herbicide tolerant transgenics in these crops. However, there are far too few concrete molecular and biochemical data published about the properties of these crops and thus there are problems in evaluating them for improvements. With the increasing use of herbicide tolerant crops, there comes an increasing use of glyphosate based herbicide sprays. In some areas glyphosate resistant weeds have developed causing farmers to switch to other herbicides. Some studies also link widespread glyphosate usage to iron deficiencies in some crops, which is both a crop production and a nutritional quality concern, with potential economic and health implications. 


\section{Risks and concerns of GM HRC}

It is generally incurred that the development of herbicide tolerant crop will encourage heavy use of herbicides. Hence, concern has been expressed about water or food contamination from increased herbicide use. Additional concern centres on use of herbicides in crops that do not metabolize the herbicide. Therefore, the unaltered herbicide could be consumed by people. As herbicide resistant crops develop, it is important to remember that no technology is ever proved to be perfectly safe. Scientists look for evidence of harm, and if none is found, conclude that there is none or that it must be looked for in a different way. Second, this technology, like all technologies (e.g., herbicides, cell phones, computers), has both its good and bad uses. We must be cautious about demonizing the potential but unknown bad effects of legitimate uses by good people and weigh them carefully against illegitimate uses by bad people.

Environmental concern: Environmental concern is related to herbicide use. It is suggested that transgenic crops have the potential to create a more sustainable agricultural system than present chemically based systems but will fail "in enabling a fully sustainable agriculture." As genetic traits that have a higher potential of enabling truly sustainable agricultural systems have not been developed due to, the lack of EPA and regulatory policies that specifically promote sustainable traits.

An agricultural biotechnology industry is dominated by agricultural chemical companies.

Patent law and industry policies prevent farmers from saving transgenic seed and thus tailoring transgenic crops to their local ecological conditions.

Social concern. Social concern is related to the following:

1. Fear that the technology will favour large farms and lead to loss of more small farms and small-scale farmers.

2. Cost of food production and food cost to the consumer will rise.

Weed control concerns. There are three major concerns related to weed control:

1. Development of herbicide resistance: Herbicide resistance among weeds may become more widespread because of continued use of an herbicide to which a crop is resistant (Sandermann, 2006).

2. Resistant gene flow to sexually compatible plants: This is acknowledged as a potential risk of introducing any genetically engineered (transgenic) crop variety. The risk is transfer of desired herbicide resistance from the crop to a weed where undesirable resistance persists by natural selection. It is worth noting that this has happened when genes from herbicide resistant canola moved to a non-weedy relative in the mustard family and then to wild mustard in a short time. The risk may be especially high where the crop and weed are closely related and can interbreed - for example, red rice and rice or Johnson grass and grain sorghum.

Once such gene(s) is transferred within wild populations, it is suggested that a selective advantage could be conferred on the recipients, so altering their biology and influencing their ecological relationship with native genotypes or other species (Lefol et al, 1997; Linder, 1998). It is considered that this could constitute a threat to biodiversity. The possibilities for transfer of any trait from crop to weed will depend on the two occurring together, their 
synchronous flowering, successful pollen transfer and compatibility of the pollen that would allow successful fertilization and embryo development. Any seed produced would then need to germinate and the trait would need to be exhibited in the resulting plant. To maintain the trait, success as a pollen donor, as a seed producer, or both, would be needed. Where a trait carrier is self fertile or where more than one individual has been produced, the $\mathrm{F}_{2}$ generation may be produced by hybrid mating, though the more likely scenario is for introgression into the recipient species' genome as a result of backcrossing. Crop plants and some weeds are derived from the same ancestors and retain a number of common characteristics. They may also still grow in close association within the geographical area in which both originated and give rise to crop-weed complexes (van Raamsdonk and van der Maesen, 1996) in which introgression of weed characters into the crops and crop characters into the weeds can occur, and may have done so over an extended period of time. Little Seed Canary Grass (Phalaris minor) is a monocot weed in the Poaceae family. In India, this weed first evolved resistance to Group C2/7 herbicides in 1991 and infests wheat. Group C2/7 herbicides are known as Ureas and Amides (Inhibition of photosynthesis at photosystem II). Research has shown that these particular biotypes are resistant to isoproturon and they may be cross-resistant to other Group C2/7 herbicides.

3. Resistant crop plants becoming hard-to-control volunteer weeds: The quite legitimate concerns of epistasis and pleiotrophy must also be recognized. Another common critique of herbicide resistant crops is that the technology will promote the use of herbicides, not decrease it, while continuing to develop what many view as an unsustainable, intensive monocultural agriculture. It is also suggested that herbicideresistant crops will reinforce farmers' dependence on outside, petroleum-based, potentially polluting technology. An associated concern is that there is no technical reason to prevent a company from choosing to develop a crop resistant to a profitable herbicide that has undesirable environmental qualities such as persistence, leachability, harm to nontarget species, and so on. It is undoubtedly true that nature's abhorrence of empty niches will mean that other weeds will move into the niches created by removal of weeds by the herbicide used in the newly resistant crop. In other words, herbicide resistance will solve some but not all weed problems. Weeds that are not susceptible to the herbicide to which the crop is resistant will appear. Development of herbicide-resistant crops is proceeding rapidly, and there are important advantages that provide good reasons for their development. Many argue that the technology will provide lower-cost herbicides and better weed control. These are powerful arguments in favour of the technology because both can lead to lower food costs for the consumer. It is also true that herbicide-resistant crops are providing solutions to intractable weed problems in some crops. Glyphosate resistance has been created in several crops. It is an environmentally favourable herbicide, and therefore, it is better to use it in lieu of other herbicides that are not environmentally favourable. An important argument in favour of the technology is that it has the potential to shift herbicide development away from initial screening for activity and selectivity and later determination of environmental acceptability to the latter occurring first. Resistance to herbicides that are environmentally favourable but lack adequate selectivity in any crops or in a major crop so their development will be profitable could be engineered and the herbicide's usefulness could be expanded greatly. This has important implications for minor crops (e.g., vegetables, fruits) where few 
herbicides are available because the market is too small to warrant the cost of development. If resistance to an herbicide already successful in a major crop (e.g., cotton) could be engineered into a minor crop, manufacturers and users would benefit. The public doubts about genetic modification of anything are raised, and it is in this context that these doubts must be addressed. Weed scientists and others involved with GMOs often think if we can just educate the public about our science, the problem will be solved as technology is already widely promoted, accepted and used.

\section{Future prospects}

Plant genetic engineering and biotechnology is now moving from the initial euphoria to the phase of course correction. Several environmental problems related to plant genetic engineering prevent realization of its full potential. One such common concern is the escape of foreign genes through pollen dispersal from transgenic crop plants engineered for herbicide resistance to their weedy relatives creating "superweeds" or causing gene pollution among other crops. Such dispersal of pollen from transgenic plants to surrounding non-transgenic plants has been well documented. The high rate of such gene flow from crops to wild relatives (as high as $38 \%$ in sunflower and $50 \%$ strawberries) is certainly a serious environmental concern. Clearly, maternal inheritance of foreign genes is highly desirable in such instances where there is no potential for out-cross (Daniell et al., 1998). Since the transgenic crops have been available for some time, we know what has been done with genetically modified herbicide resistant crops. The technology is so new and changing so rapidly that we do not-perhaps cannot-know what might be done. That is, the direction of research is clear, but the final destination is not. We cannot be sure what new possibilities will be discovered as the technology of herbicide resistance continues to develop rapidly. Adoption of molecular-based methods in weed science research will bring a new dimension to the science and can have "far reaching benefits in agriculture and biotechnology" (Marshall, 2001). One potential benefit of genomics research is the discovery of new targets for herbicide action (Hess et al., 2001). Other benefits may include identification and use of genes that contribute to a crop's competitive ability (e.g., early shoot emergence, rapid early growth, fast canopy closure, production of allelochemicals). Genomics may also discover genes that contribute to weediness, a plant's perennial growth habit, seed dormancy, and allelopathy (Weller et al., 2001).

\section{References}

Annual Report. (2008). National Research Centre on Weeds. Jabalpur. (M.P.).

Bell, A. (1998). Microtubule inhibitors as potential antimalarial agents. Parasitol. Today, 14: 234-240.

Buchanan-Wollaston, V., Snape, A. and Cannon, F. (1992). A plant selectable marker gene based on the detoxification of the herbicide dalapon. Plant Cell Rep., 11: 627-631.

Chan, M. M. Y., Grogl, M., Chen, C. C., Bienen, E. J. and Fong, D. (1993). Herbicides to curb human parasitic infections-in vitro and in vivo effects of trifluralin on the trypanosomatid protozoans. Proc. Natl. Acad. Sci., 90: 5657-5661. 
Cohen, M. B., Jackson, M. T., Lu, B. R., Morin, S. R., Mortimer, A. M., Pham, J. L. and Wade, L. J. (1999). Predicting the environmental impact of transgene outcrossing in wild and weedy rices in Asia. In: Gene flow in agriculture: relevance for transgenic crops. (pp. 151-157).

Comai, L., Facciotti, D., Niatt, W. R., Thompson, G., Rose, R. E. and Stalker, D. M. (1985). Expression in plants of a mutant aroA gene from Salmonella typhinurium confers tolerance to glyphosate. Nature, 317: 741-744.

Daniell, H., Datta, R., Varma, S., Gray, S. and Lee, S. B. (1998). Containment of herbicide resistance through genetic engineering of the chloroplast genome. Nat Biotechnol., 16: 345-348.

Deisenhofer, J. and Michel, H. (1989). The photosynthetic reaction center from the purple bacterium (Rhodopseudomonas viridis). Science, 245: 1463-1473.

Duke, S.O. (1990). Overview of herbicide mechanisms of action. Env. Health Perspectives, 87:263-271.

Duke, S.O., J. Lydon, J.M. Becerril, T.D. Sherman, L.P. Lettnen, Jr., and H. Matsumoto. (1991).Protoporphyrinogen oxidase-inhibiting herbicides. Weed Sci., 39:465473.

Feng, P. C. C., Ruff, T. G., Rangwala, S. H. and Rao, S. R. (1998). Engineering plant resistance in thiazopyr herbicide via expression of a novel esterase deactivation enzyme. Pest Biochem Physiol., 59: 89-103.

Freyssinet, G., Pelissier, B., Freyssinet, M. and Delon, R. (1996). Crops resistant to oxynils: from the laboratory to the market. Field Crops Res., 45: 125-133.

Gressel, J. and Segel, L. A. (1978). The paucity of genetic adaptive resistance of plants to herbicides: possible biological reasons and implications. J. Theor. Biol., 75: 349371.

Gressel, J. (1988). Multiple resistances to wheat selective herbicides: New challenges to molecular biology. Oxford Surveys of Plant Mol. Cell Biol., 5: 195-203.

Gressel, J. (1999a). Tandem constructs; preventing the rise of superweeds. Trends Biotechnol., 17: 361-366.

Gressel, J. (1999b). Needed: New paradigms for weed control. In: Weed Management in the 21st Century: Do we Know Where we are Going? (pp. 462-486) Proc. of the 12th Australian Weeds Conference, Hobart, Tasmania.

Gressel, J. (1999c). Herbicide resistant tropical maize and rice: Needs and biosafety considerations. Brighton Crop Protection Conference-Weeds pp. 637-645.

Harvey, B. M. R. and Harper, D. B (1982). Tolerance to bipyridylium herbicides. In: LeBaron H and Gressel J (eds) Herbicide Resistance in Plants (pp. 215-234) Wiley, New York.

Hess, F.D., R.J. Anderson, and J.D. Reagan. (2001). High throughput synthesis and screening:The partner of genomics for discovery of new chemicals for agriculutre. Weed Sci., 49:249-256.

Inui, H., Ueyama, Y., Shiota, N., Ohkawa, Y. and Ohkawa, H. (1999). Herbicide metabolism and cross-tolerance in transgenic potato plants expressing human CYP1A1. Pestic Biochem Physiol., 64: 33-46. 
Jepson, I., Holt, D. C., Roussel, V., Wright, S. Y. and Greenland, A. J. (1997). Transgenic plant analysis as a tool for the study of maize glutathione transferases. In: Hatzios KK (ed.), Regulation of Enzymatic Systems Detoxifying Xenobiotics in Plants. pp. 313323.

LaRossa, R. A. and Schloss, J. V. (1984). The sulfonylurea herbicide sulfometuron methyl is an extremely potent and selective inhibitor of acetolactate synthase in Salmonella typhimurium. J. Biol. Chem., 25: 8753-8757.

Lefol, E., Séguin-Swartz, G. and Downey, R. K.(1997). Sexual hybridisation in crosses of cultivated Brassica species with the crucifers Erucastrum gallicum and Raphanus raphanistrum: Potential for gene introgression. Euphytica, 95: 127-139.

Linder, C. R. (1998). Potential persistence of transgenes: seed performance of transgenic canola and wild x canola hybrids. Ecological Applications, 8: 1180-1195.

Ling-Hwa, T. and Morishima, H. (1997). Genetic characterization of weedy rices and the inference on their origins. Breeding Sci., 47: 153-160.

Majumder, N. D., Ram, T. and Sharma, A. C. (1997). Cytological and morphological variation in hybrid swarms and introgressed population of interspecific hybrids (Oryza rufipogon Griff _ Oryza sativa L) and its impact on evolution of intermediate types. Euphytica, 94: 295-302.

Mariam, A. L., Zakri, A. H., Mahani, M. C. and Normah,M. N. (1996). Interspecific hybridization of cultivated rice, Oryza sativa L with the wild rice, O minuta Presl. Theor. Appl. Genet., 93: 664-671

Martin, C., Juliano, A., Newbury, H. J., Lu, B. R., Jackson, M. T. and Ford Lloyd, B. V. (1997). The use of RAPD markers to facilitate the identification of Oryza species within a germplasm collection. Genet. Resour.\& Crop Evol., 44: 175-183.

Marshall, G. (2001). A perspective on molecular-based research: Integration and utility in weed science. Weed Sci., 49:273-275.

Malan,C., Greyling, M. M. and Gressel, J. (1990). Correlation between antioxidant enzymes, $\mathrm{CuZn}$ SOD and glutathione reductase, and environmental and xenobiotic stress tolerance in maize inbreds. Plant Sci., 69: 157-166.

Mayo, C. M., Horak, M. J., Peterson, D. E. and Boyer, J. E. (1995). Differential control of four Amaranthus species by six post emergence herbicides in soybean (Glycine max). Weed Tech., 9: 141-147.

Michel, H. and Deisenhofer, J. (1988). Relevance of the photosynthetic reaction center from purple bacteria to the structure of photosystem II. Biochemistry, 27: 17.

Morishima, H. (1984). Species relationships and the search for ancestors In: Tsunoda S and Takahashi N (eds) Biology of Rice, pp. 3-30.

Oard, J. H., Linscombe, S. D., Bravermann, M. P., Jodari, F., Blouin, D. C. and Leech, M. (1996). Development, field evaluation, and agronomic performance of transgenic herbicide resistant rice. Mol. Breeding, 2: 359-368.

Sankula, S., Braverman, M. P., Jodari, F., Linscombe, S. D. and Oard, J. H. (1997a). Evaluation of glufosinate on rice (Oryza sativa) transformed with the bar-gene and red rice (Oryza sativa). Weed Tech., 11: 70-75. 
Sankula, S., Braverman, M. P. and Linscombe, S. D. (1997b). Response of bar-transformed rice (Oryza sativa) transformed with the bar gene and red rice to glufosinate application timing. Weed Tech.,11: 303-307.

Shah, D. M., Horsch, R. B., Klee, H. J., Kishore, G. M., Winter, J. A., Tumer, N. E., Hironaka, C. M., Sanders, P. R., Gasser, C. S., Aykent, S., Siegel, N. R., Rogers, S. G. and Fraley, R. T. (1986).Engineering herbicide tolerance in transgenic plants. Science, 233: 478-481.

Shaner, D. L.,Anderson, P. C. and Stidham, M. A. (1984).Potent inhibitors of acetohydroxyacid synthase. Plant Physiol., 76: 545-546.

Siminsky, B., Corbin, F. T., Ward, E. R., Fleishmann, T. J. and Dewey, R.(1999). Expression of a soybean cytochrome P450 monooxygenase cDNA in yeast and tobacco enhances the metabolism of phenylurea herbicides. Proc. Natl. Acad. Sci., 96: 17501755.

Skipsey, M., Andrews, C. J., Townson, J. K., Jepson, I. and Edwards, R.(1997). Substrate and thiol specificity of a stress-inducible glutathione transferase from soybean. FEBS Lett., 409: 370-374.

Streber, W. R. and Willmitzer. L. (1989). Transgenic tobacco plants expressing a bacterial detoxifying enzyme are resistant to 2,4-D. BioTechnology, 7: 811816.

Thompson, C. J., Movva, N. R., Tizard, R., Crameri, R., Davies, J. E., Lauwereys, M. and Botterman, J. (1987). Characterization of the herbicide-resistance gene bar from Streptomyces hygroscopicus. EMBO J., 6: 2519-2523.

Van Raamsdonk, L. W. D. and van der Maesen, L. J. G.(1996). Crop-weed complexes: the complex relationship between crop plants and their wild relatives. Acta Botanica Neerlandica, 45: 135-155.

Varshney, J.G. and Mishra , J.S. (2008). Role of herbicides in weed management and food security. Crop Care , 34: 67-73.

Vasil, I. K. (1996). Phosphinothricin resistant crops. In: Duke SO (ed.) Herbicide resistant crops: Agricultural, environmental, economic, regulatory, and technical aspects pp. 85-92.

Weeks, J. T., Anderson, O. D. and Blechl, A. E. (1993). Rapid production of multiple independent lines of fertile transgenic wheat (Triticum aestivum). Plant Physiol., 102: 1077-1084.

Weller, S.C., R.A. Bressan, P.B. Goldsbrough, T.B. Fredenburg, and P.M. Hasegawa. (2001). The effect of genomics on weed management in the 21st century. Weed Sci. 49:282289.

Wetzel, D. K., Horak, M. J., Skinner, D. Z. and Kulakow, P. A. (1999b). Transferal of herbicide resistance from Amaranthus palmeri to Amaranthus rudis. Weed Sci., 47: 538-543.

Wohlleben, W., Arnold, W., Broer, I., Hillemann, D., Strauch, E. and Pu“ hler, A. (1988). Nucleotide sequence of the phosphinothricin $N$-acetyltransferase gene from Streptomyces viridochromogenes Tu" 494 and its expression in Nicotiana tabacum. Gene, 70: 25-37. 
Ye, B., Faltin, H., Ben-Hayyim, G., Eshdat, Y. and Gressel, J. (2000). Correlation of glutathione peroxidase to paraquat/oxidative stress resistance in Conyza: determined by direct fluorometric assay. Pestic. Biochem. Physiol., 66: 182194. 


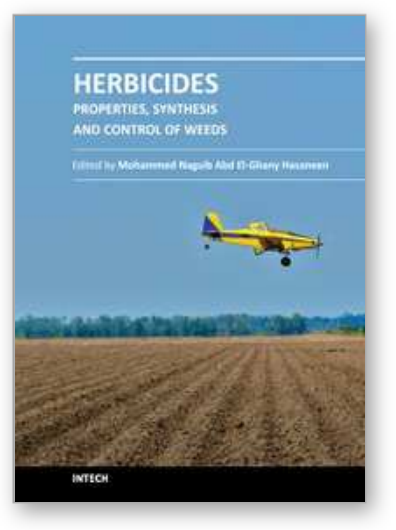

\author{
Herbicides - Properties, Synthesis and Control of Weeds \\ Edited by Dr. Mohammed Nagib Hasaneen
}

ISBN 978-953-307-803-8

Hard cover, 492 pages

Publisher InTech

Published online 13, January, 2012

Published in print edition January, 2012

This book is divided into two sections namely: synthesis and properties of herbicides and herbicidal control of weeds. Chapters 1 to 11 deal with the study of different synthetic pathways of certain herbicides and the physical and chemical properties of other synthesized herbicides. The other 14 chapters (12-25) discussed the different methods by which each herbicide controls specific weed population. The overall purpose of the book, is to show properties and characterization of herbicides, the physical and chemical properties of selected types of herbicides, and the influence of certain herbicides on soil physical and chemical properties on microflora. In addition, an evaluation of the degree of contamination of either soils and/or crops by herbicides is discussed alongside an investigation into the performance and photochemistry of herbicides and the fate of excess herbicides in soils and field crops.

\title{
How to reference
}

In order to correctly reference this scholarly work, feel free to copy and paste the following:

N.P. Singh and Indu Singh Yadav (2012). Herbicide Tolerant Food Legume Crops: Possibilities and Prospects, Herbicides - Properties, Synthesis and Control of Weeds, Dr. Mohammed Nagib Hasaneen (Ed.), ISBN: 978953-307-803-8, InTech, Available from: http://www.intechopen.com/books/herbicides-properties-synthesisand-control-of-weeds/herbicide-tolerant-food-legume-crops-possibilities-and-prospects

\section{INTECH}

open science | open minds

\author{
InTech Europe \\ University Campus STeP Ri \\ Slavka Krautzeka 83/A \\ 51000 Rijeka, Croatia \\ Phone: +385 (51) 770447 \\ Fax: +385 (51) 686166 \\ www.intechopen.com
}

\author{
InTech China \\ Unit 405, Office Block, Hotel Equatorial Shanghai \\ No.65, Yan An Road (West), Shanghai, 200040, China \\ 中国上海市延安西路65号上海国际贵都大饭店办公楼 405 单元 \\ Phone: +86-21-62489820 \\ Fax: +86-21-62489821
}


(C) 2012 The Author(s). Licensee IntechOpen. This is an open access article distributed under the terms of the Creative Commons Attribution 3.0 License, which permits unrestricted use, distribution, and reproduction in any medium, provided the original work is properly cited. 